\title{
EARLINET observations of the 14-22-May long-range dust transport event during SAMUM 2006: validation of results from dust transport modelling
}

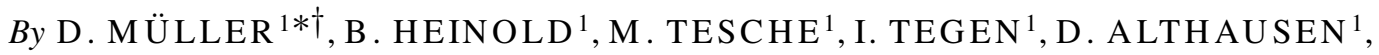

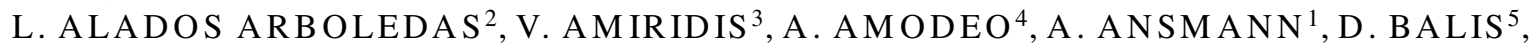 \\ A. COMERON ${ }^{6}$, G. D' AMICO ${ }^{4}$, E. GERASOPOULOS ${ }^{3}$, J. L. GUERRERO-RASCADO ${ }^{6}$, \\ V. FREUDENTHALER ${ }^{7}$, E. GIANNAKAKI ${ }^{5}$, B. HEESE ${ }^{1}$, M. IARLORI $^{8}$, P. KNIPPERTZ $^{9}$, \\ R. E. MAMOURI ${ }^{10}$, L. MONA ${ }^{4}$, A. PAPAYANNIS ${ }^{10}$, G. PAPPALARDO ${ }^{4}$, R.-M. PERRONE ${ }^{11}$, \\ G. PISANI ${ }^{12}$, V. RIZI ${ }^{8}$, M. SICARD ${ }^{6}$, N. SPINELLI ${ }^{12}$, A. TAFURO ${ }^{11}$ and M. W IEGNER ${ }^{7}, \quad{ }^{1}$ Leibniz \\ Institute for Tropospheric Research, Leipzig, Germany; ${ }^{2}$ Andalusian Center for Environmental Studies, University of \\ Granada, Granada, Spain; ${ }^{3}$ National Observatory of Athens, Athens, Greece; ${ }^{4}$ Istituto di Metodologie per l'Analisi \\ Ambientale - Consiglio Nazionale delle Ricerche, Tito Scalo, Potenza, Italy; ${ }^{5}$ Laboratory of Atmospheric Physics, \\ Aristotle University of Thessaloniki, Thessaloniki, Greece; ${ }^{6}$ Universitat Politécnica de Catalunya, Barcelona, Spain; \\ ${ }^{7}$ Meteorological Institute, Ludwig Maximilian University, Munich, Germany; ${ }^{8}$ Dipartimento di Fisica, Universitá degli \\ Studi - L'Aquila, L'Aquila, Italy; ${ }^{9}$ Institute for Atmospheric Physics, Johannes Gutenberg University, Mainz, Germany; \\ ${ }^{10}$ Physical Department, National Technical University of Athens, Athens, Greece, ${ }^{11}$ Istituto Nazionale per la Fisica \\ della Materia, Universitá degli Studi di Lecce, Italy; ${ }^{12}$ Consorzio Nazionale Interuniversitario per le Scienze Fisiche \\ della Materia and Dipartimento di Scienze Fisiche - Universitá degli Studi di Napoli “Federico II", Naples, Italy
}

(Manuscript received 9 July 2008, in final form 20 October 2008)

\section{ABSTRACT}

We observed a long-range transport event of mineral dust from North Africa to South Europe during the Saharan Mineral Dust Experiment (SAMUM) 2006. Geometrical and optical properties of that dust plume were determined with Sun photometer of the Aerosol Robotic Network (AERONET) and Raman lidar near the North African source region, and with Sun photometers of AERONET and lidars of the European Aerosol Research Lidar Network (EARLINET) in the far field in Europe. Extinction-to-backscatter ratios of the dust plume over Morocco and Southern Europe do not differ. Ångström exponents increase with distance from Morocco. We simulated the transport, and geometrical and optical properties of the dust plume with a dust transport model. The model results and the experimental data show similar times regarding the appearance of the dust plume over each EARLINET site. Dust optical depth from the model agrees in most cases to particle optical depth measured with the Sun photometers. The vertical distribution of the mineral dust could be satisfactorily reproduced, if we use as benchmark the extinction profiles measured with lidar. In some cases we find differences. We assume that insufficient vertical resolution of the dust plume in the model calculations is one reason for these deviations.

\section{Introduction}

This contribution is the companion paper to the publication by Heinold et al. (2008) who present results from the regional

\footnotetext{
* Corresponding author.

e-mail: detlef@tropos.de

${ }^{\dagger}$ Now at: Atmospheric Remote Sensing Laboratory, Department of Environmental Science and Engineering, Gwangju Institute of Science and Technology, Gwangju, South Korea

DOI: $10.1111 /$ j.1600-0889.2008.00400.x
}

dust model system LM-MUSCAT-DES (LM = Lokal Modell; MUSCAT $=$ MUltiScale Chemistry Aerosol Transport Model; DES $=$ dust emission scheme). The model is used to describe the conditions of Saharan dust observed in Morocco during the Saharan Mineral Dust Experiment (SAMUM) 2006. The model simulates Saharan dust emission, the transport and deposition of dust, and the effect of dust on the radiation balance (Heinold et al., 2007). In our paper we extend the simulations on dust transport into the far field of the North African source region.

The performance of the regional dust model system LMMUSCAT-DES was evaluated with data of particle optical 
depths, extinction coefficients, and particle size distributions. Data were collected with remote sensing and in-situ instrumentation in Morocco. Heinold et al. (2008) evaluated the performance of the model for two time periods in May and June 2006 with focus on dust properties observed over the Moroccan field sites on 19 and 20 May 2006, and 3 and 4 June 2006. The authors find rather good agreement between the modelled and the measured dust optical thicknesses and dust particle size distributions. The spatio-temporal evolution of the dust plumes in contrast was not always reproduced. Another result of the study by Heinold et al. (2008) is that the model finds the correct maximum value of the dust extinction coefficient along the vertical scale of the dust layer, if source and transport of the dust plume are correctly simulated. However the model does not reproduce well the strong gradients of dust extinction coefficients that occurred at the top of the dust layer during SAMUM 2006 (Heinold et al., 2008).

In summary, the model system is generally capable of describing the north Saharan dust cycle. In particular dust events related to synoptic-scale meteorology and long-range transport of dust agree well with the observations. However, the evaluation of the model results with the large number of available observations in proximity to dust source regions demonstrates the limits of the regional dust model system (Heinold et al., 2008).

We extend the study by Heinold et al. (2008) into the far field of the dust source on the basis of a long-range transport event that began around 14 May 2006. At that time Saharan dust was transported from Morocco to the Iberian peninsula and from there across South Europe to Greece, where the dust plume arrived around 20 May 2006. The dust plume was observed with the lidars of the European Aerosol Research Lidar Network (EARLINET) (Bösenberg et al., 2003; Matthias et al., 2004) and Sun photometers at the lidar stations.

Lidar observations in Spain, Italy, and Greece provide us with vertically resolved information on the geometrical and optical properties of the dust plume in the far field of the source region. The observations at the SAMUM field site provide us with the properties of the dust plume, just before it left the African source region. Thus, this work also presents an extension of a previous study of dust long-range transport observed within EARLINET (Ansmann et al., 2003). In that previous case study dust was carried across west and central Europe, but we did not have information on the properties of the dust plume at its North African source region. Our study also provides a useful link to Saharan dust long-term observations which are carried out in the framework of EARLINET since 2000 (Papayannis et al., 2005, 2008; Mona et al., 2006).

In our case study, the EARLINET sites provide us with a valuable set of data for model validation. One has to keep in mind that the comparison of modelled dust optical thickness with satellite indices, provided by Ozone Monitoring Instrument (OMI) (Levelt, 2002) and Meteosat Second Generation (MSG) (Schmetz et al., 2002) can only be qualitative, as no quantitative dust information can be obtained over land from remote sensing with these instruments yet.

In Section 2, we summarize the methodology. In Section 3, we describe the geometrical and optical properties of the dust plume. We compare the properties of the dust plume over South Europe to the same properties measured in Morocco. In Section 4, we compare our results for South Europe to the results from the dust model simulations. In Section 5, we close our contribution with a summary.

\section{Methodology}

\subsection{EARLINET lidar stations}

The European Aerosol Research Lidar Network (EARLINET) is a network of 25 European lidar stations (status as of May 2008). Each lidar group performs observations on a routine base several times per week since May 2000. EARLINET is the follow-up network to the German lidar network that was operational from September 1997 until April 2000 (Bösenberg et al., 2001). One goal of EARLINET is to establish a quantitative database of both horizontal and vertical distribution of aerosols on a continental scale. In addition to the regular observations, lidar measurements are also carried out during so-called special events as, for instance, large-scale transport of Saharan dust to Europe.

Figure 1 shows the current distribution of EARLINET lidar stations. The stations that carried out observations in the time from 14 to 23 May 2006 are marked with yellow circles. A

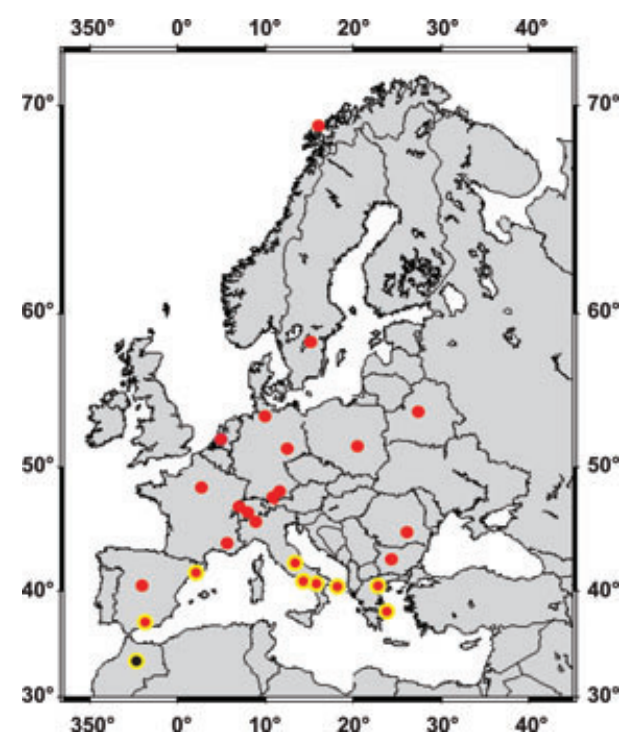

Fig. 1. Location of EARLINET lidar stations (red bullets). Yellow circles denote lidar stations that reported mineral dust in the investigated timeframe. The lidar station that was operated in Morocco during SAMUM is also shown (black bullet with yellow circle). 
description of the different instruments can be found in Bösenberg et al. (2003).

Briefly, most systems are multiwavelength lidars which allow us to determine the particle backscatter coefficient $\beta(\lambda)$ at several measurement wavelengths $\lambda$. A detailed description on how that analysis is performed can be found in Ansmann and Müller (2005).

From these observations backscatter-related Ångström exponents $\stackrel{\circ}{\beta}_{\beta}\left(\lambda_{1}, \lambda_{2}\right)$ are determined. This exponent describes the spectral dependence of the backscatter coefficient. It is defined as

$\stackrel{\circ}{\mathrm{a}}_{\beta}\left(\lambda_{1}, \lambda_{2}\right)=\ln \left[\beta\left(\lambda_{2}\right) / \beta\left(\lambda_{1}\right)\right] / \ln \left(\lambda_{1} / \lambda_{2}\right)$.

The expressions $\beta\left(\lambda_{1}\right)$ and $\beta\left(\lambda_{2}\right)$ describe backscatter coefficients at two different measurement wavelengths $\lambda_{1}$ and $\lambda_{2}$, respectively.

Several Raman lidars of the network measure the nitrogen Raman signal at $387 \mathrm{~nm}$ (355-nm primary wavelength) and/or $607 \mathrm{~nm}$ (532 primary wavelength) in addition to the elastic backscatter signals at the laser wavelengths. From these observations the volume extinction coefficient $\alpha(\lambda)$ and the volume backscatter coefficient of the particles can be determined (Ansmann et al., 1992).

From $\beta(\lambda)$ and $\alpha(\lambda)$ we determine the extinction-tobackscatter ratio (lidar ratio) $S(\lambda)$. This quantity is sensitive to particle size and complex refractive index. Because this parameter contains the particle backscatter coefficient, the lidar ratio also is sensitive to the geometrical shape of the particles. In contrast, the particle extinction coefficient does not depend on particle shape in a significant way (Mishchenko et al., 1997; Kalashnikova and Sokolik, 2002; Müller et al., 2003).

Measurements of the particle extinction coefficient at two wavelengths allow us to determine the extinction-related Ångström exponent $\stackrel{\circ}{\alpha}_{\alpha}\left(\lambda_{1}, \lambda_{2}\right)$. This parameter is defined as

$\mathrm{a}_{\alpha}\left(\lambda_{1}, \lambda_{2}\right)=\ln \left[\alpha\left(\lambda_{2}\right) / \alpha\left(\lambda_{1}\right)\right] / \ln \left(\lambda_{1} / \lambda_{2}\right)$.

\subsection{Sun photometers}

Particle optical depth of the atmospheric column and columnmean Ångström exponents were determined with Sun photometers at all EARLINET lidar stations considered in our study, except at L'Aquila. We add results of a Sun photometer station in Rome (Rome Tor Vergata at $41.5^{\circ} \mathrm{N}, 12.4^{\circ} \mathrm{E}$ ) which is about $113 \mathrm{~km}$ to the west of the lidar station in L'Aquila. Except for a multi-filter rotational shadowband spectrometer at the EARLINET station in Athens all other instruments are Sun photometers operated by the Aerosol Robotic Network (AERONET).

The instrument type at the Athens stations is an MFR-7 Yankee (Env. System Inc., Turner Falls, MA). The spectrometer provides 1-min averages of particle optical depth at five wavelengths $(415,501,615,675$ and $867 \mathrm{~nm})$. The methodology of extracting particle optical depth, direct solar irradiance, and all applied corrections is described in detail by Gerasopoulos et al. (2003).

AERONET is a federated network of Sun photometer stations. The instrument characteristics are described in detail by Holben et al. (1998). Briefly, spectral observations of Sun direct irradiance are made at 340, 380, 440, 500, 670, 870, 940 and $1020 \mathrm{~nm}$. Measurements of sky radiance are made at 440, 670, 870 and $1020 \mathrm{~nm}$. Details of the calibration procedure of the instruments are given by Holben et al. (1998, 2001).

From these signals one determines particle optical depth and scattering phase functions. Microphysical properties such as particle size distributions and complex refractive indices are determined, too. A detailed description of the data analysis can be found in Dubovik and King (2000). Details on error analysis are given by Dubovik and King (2000) and Dubovik et al. (2000). In this contribution we will only present particle optical depth and Ångström exponents.

\subsection{Instruments at the SAMUM field sites}

Raman lidar and Sun photometer observations were carried out in Morocco. The Raman lidars were operated at the SAMUM field site at Ouarzazate $\left(30.93^{\circ} \mathrm{N}, 6.9^{\circ} \mathrm{W}\right)$. The systems are described in detail by Tesche et al. (2008) and Freudenthaler et al. (2008). The lidar systems provide us with particle backscatter and extinction coefficients, Ångström exponents, and lidar ratios at the same measurement wavelengths that are used by the EARLINET lidars. Linear particle depolarization ratios were determined at 355, 532, 710 and $1064 \mathrm{~nm}$. Data analysis and error analysis procedures for the lidar data are discussed in detail by Tesche et al. (2008). We also operated one AERONET Sun photometer at the field site.

\subsection{Model}

The simulations of Saharan dust transport presented here were carried out with the regional dust modelling system LMMUSCAT-DES, for which a detailed description is given in Heinold et al. (2007). The model consists of the mesoscale meteorological model Lokal Modell (LM) (Doms and Schättler, 2002) which is provided by the German weather service (Deutscher Wetterdienst, DWD), the online-coupled MUltiScale Chemistry Aerosol Transport Model (MUSCAT) (Wolke et al., 2004a,b), and a dust emission scheme which is based on the work of Tegen et al. (2002). Dust emission, transport, and deposition are simulated with MUSCAT with the use of the meteorological and hydrological fields that are computed by the LM. Surface properties (vegetation, surface roughness, soil texture, soil moisture content) and the location of preferential dust sources are considered for dust flux calculations. Soil erosion by wind mostly depends on the wind shear stress on the ground. Soil erosion occurs when the surface friction velocity increases above a certain soil-size dependent threshold friction velocity. We have lowered 
that threshold friction velocity by a factor of 0.66 in order to compensate for lower model winds (Heinold et al., 2007). Local wind systems, clouds, precipitation, and mesoscale convection are simulated depending on topography, subgridscale moist convection is parameterized following Tiedtke (1989). The modelled dust is transported as a passive tracer in five independent size classes with diameter limits at $0.2,0.6,1.7,5.3,16$ and $48 \mu \mathrm{m}$. The aerosol deposition parameterization in LMMUSCAT is adapted with respect to dust particle density and washout efficiency. Dry deposition of dust is parameterized as proposed by Zhang et al. (2001). For particles larger than 2 $\mu \mathrm{m}$ the removal from the atmosphere is mainly by gravitational settling. Wet deposition, both in-cloud and subcloud removal, is parameterized following Berge (1997) and Jakobson et al. (1997). In the model, the radiative flux computation accounts for the variability in the spatio-temporal distribution of modelled dust aerosol, and the direct dust radiative effect can affect meteorology and dust load (Helmert et al., 2007). Dust optical properties are derived from Mie-scattering theory using the refractive indices from laboratory measurements by Sokolik and Toon (1999), assuming an internal mixture of $2 \%$ hematite and $98 \%$ kaolinite.

The dust model was run for the period from 9 May to 5 June 2006. In this contribution we focus on the long-range dust transport case that occurred during SAMUM 2006 on the days of 14-23 May, when Saharan dust was transported across the Mediterranean basin. The model domain covers the area $13.86^{\circ} \mathrm{N}, 25.35^{\circ} \mathrm{W}-47.78^{\circ} \mathrm{N}, 38.16^{\circ} \mathrm{E}$. We use a horizontal resolution of $28 \times 28 \mathrm{~km}$ and 40 vertical layers. The LM runs are initialized using analysis fields from the global model GME (Majewski et al., 2002). The LM runs are driven by 6-hourly updated lateral boundary conditions from the GME. In order to keep the meteorology of the regional model close to the analysis fields, the simulations were performed in 48-h cycles with a spin-up time of $24 \mathrm{~h}$ for the LM. After this time MUSCAT is coupled to compute dust mobilization and transport. At the first cycle, the initial dust concentration is set to zero. The following cycles are initialized using the modelled dust concentration from the previous cycle.

For the model evaluation, the modelled dust concentration is transferred to the dust optical thickness at $500 \mathrm{~nm}$ wavelength with

$\tau=\sum_{j} \sum_{k}\left[\frac{3}{4} \frac{Q_{\mathrm{ext}, 500}(j)}{r_{\mathrm{eff}}(j) \rho_{p}(j)}, c_{\mathrm{dust}}(j, k) \Delta z(k)\right]$.

The expression $Q_{\text {ext, } 500}(j)$ is the extinction efficiency at $500 \mathrm{~nm}$ of the dust mode $j, r_{\text {eff }}(j)$ is the effective radius of dust particles of mode $j, c_{\text {dust }}(j, k)$ is the dust concentration of the dust mode $j$ at the vertical level $k$ and $\Delta z(k)$ is the depth of the vertical level $k$. For the evaluation of the simulated dust distribution, the extinction efficiency $Q_{\text {ext, } 500}(j)$ is calculated from Mie-scattering theory and the use of dust refractive indices from Sinyuk et al. (2003).

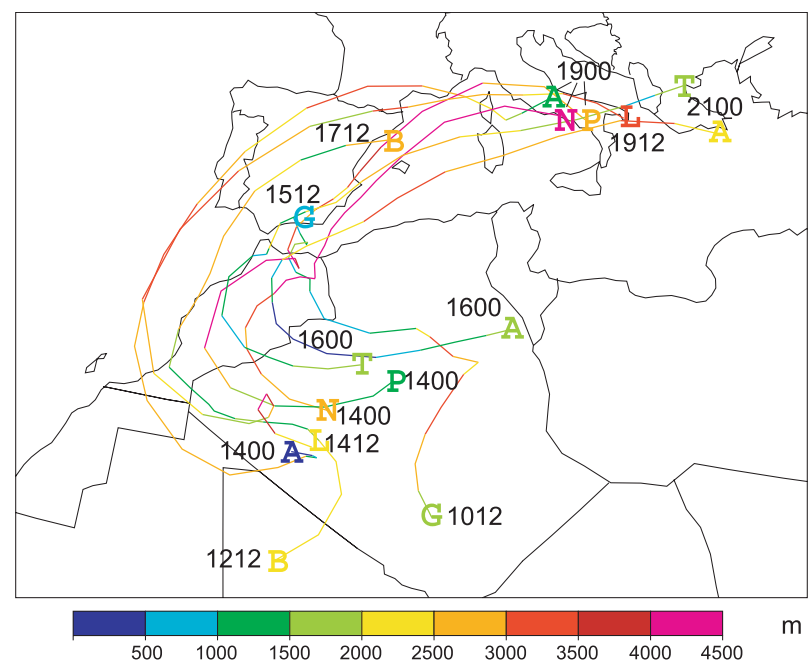

Fig. 2. Selected 5-d backward trajectories started from gridpoints close to the locations of the eight EARLINET stations Granada $(\mathrm{G})$, Barcelona (B), L'Aquila (A), Naples (N), Potenza (P), Lecce (L), Athens (A) and Thessaloniki (T). The numbers indicate the trajectory start and times (in UTC). The trajectories and the letters indicating the stations are colour-coded with height above ground in $\mathrm{m}$. The trajectories are started from within the dust layer according to the lidar profiles shown in Fig. 6.

\section{Observations}

\subsection{Meteorological situation and dust distribution}

The meteorological conditions of the main dust episodes during the 2006 SAMUM field campaign are described in detail by Knippertz et al. (2008) and are summarized here with the help of 5-d trajectories linking EARLINET stations in southern Europe with dust sources in northern Africa (Fig. 2), and horizontal distributions of the OMI aerosol absorption index (AI) (Fig. 3). Blue areas in Fig. 3 indicate clouds that obscured the dust plume.

During 11-14 May 2006 an upper-level short wave trough crossed northwestern Africa and triggered the formation of a lee cyclone east of the Atlas Mountains (Knippertz et al., 2008). The subsequent surge of cold air from the Mediterranean Sea accompanied by strong winds activated dust sources in western Tunisia as well as eastern and central Algeria as indicated by the OMI AI distribution on 14 May 2006 (Fig. 3a). Along the northern flank of this cyclone, dust-laden air was advected into southern Morocco as shown by the trajectories labeled ' $B$ ' and ' $G$ ' in Fig. 2. Between 15 and 17 May 2006 an upper-level ridge established over northwestern Africa, with a surface high centered over the eastern Atlas. Moderately dust-laden air from eastern and central Algeria was transported with the anticyclonic flow to the Moroccan coast and then towards the Iberian Peninsula (Figs. 2 and $3 b$ ). The dust plume passed over the two EARLINET stations at Granada and Barcelona during this period as indicated by both OMI AI and trajectories. By 18 May 2006 the 
Fig. 3. Horizontal distribution of the aerosol index derived from OMI observations (overpass at 13:45 local time). That index indicates the presence of dust. The higher the index the more likely dust was observed. Model results (LM-Muscat-DES) of the horizontal distribution of optical depth at $550 \mathrm{~nm}$ wavelength at 12 UTC are presented in the right column. Shown are the results on (a, b) 14 May, (c,d) 16 May, (e, f) 18 May, (g, h) 20 May, and (i, j) 22 May 2006. The abbrevations denote the following stations: AT (Athens), BA (Barcelona), GR

(Granada), LA (L'Aquila), LE (Lecce), NA (Naples), ORZ (Ouarzazate), PO (Potenza) and TH (Thessaloniki).
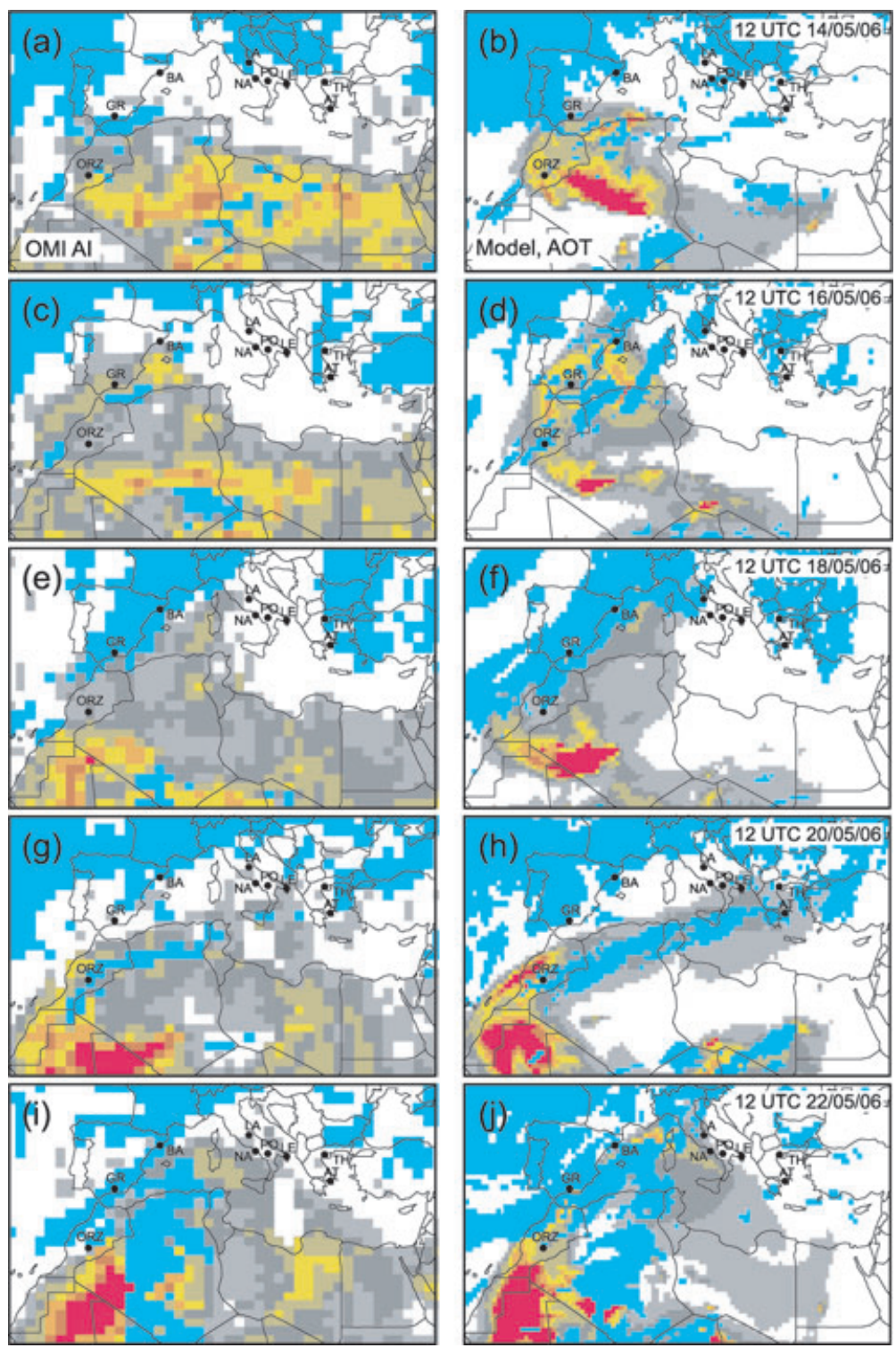

dust plume covered the western Mediterranean and approached the EARLINET station at L'Aquila (3c). Backward trajectories that started on 19 May from the four Italian EARLINET stations all show an anticyclonic track from western Algeria across the Iberian Peninsula and suggest a connection to the dust event on 14 May (see Fig. 3a). On 20 May 2006 the dust plume stretched across southern Italy into Greece (Fig. 3d), where parts of it remained until 22 May 2006 (Fig. 3e). Backward trajectories from Athens and Thessaloniki, started at 0:00 UTC 21 May, show a path similar to the trajectories for the Spanish and Italian stations, but the corresponding airmass was delayed by about 2-4 d. This path suggests a link with dust being mobilized over Algeria in the aftermath of the event described by Knippertz et al. (2008). Most of the dust transport occured in the lower half of the troposphere as indicated by the gray shaded areas in Fig. 2.

\subsection{Sun photometer observations of the dust plume over South Europe}

In this section we present results of Sun photometer observations. The data rather likely describe a mixture of mineral dust with anthropogenic pollution. Anthropogenic pollution is ubiquitous in the boundary layer over the South European lidar/Sun photometer stations considered in this study. In Section 3.4, we will present optical properties of the mineral dust plume in the free troposphere on the basis of lidar observations. In that case the data describe mineral dust that was rather unaffected with anthropogenic pollution.

AERONET Sun photometer observations at the SAMUM lidar field site at Ouarzazate showed daily-mean dust optical depths of $0.44 \pm 0.04$ at $500 \mathrm{~nm}$ on 13 May 2006, and $0.66 \pm 0.19$ on 14 May 2006. Ångström exponents from dust 

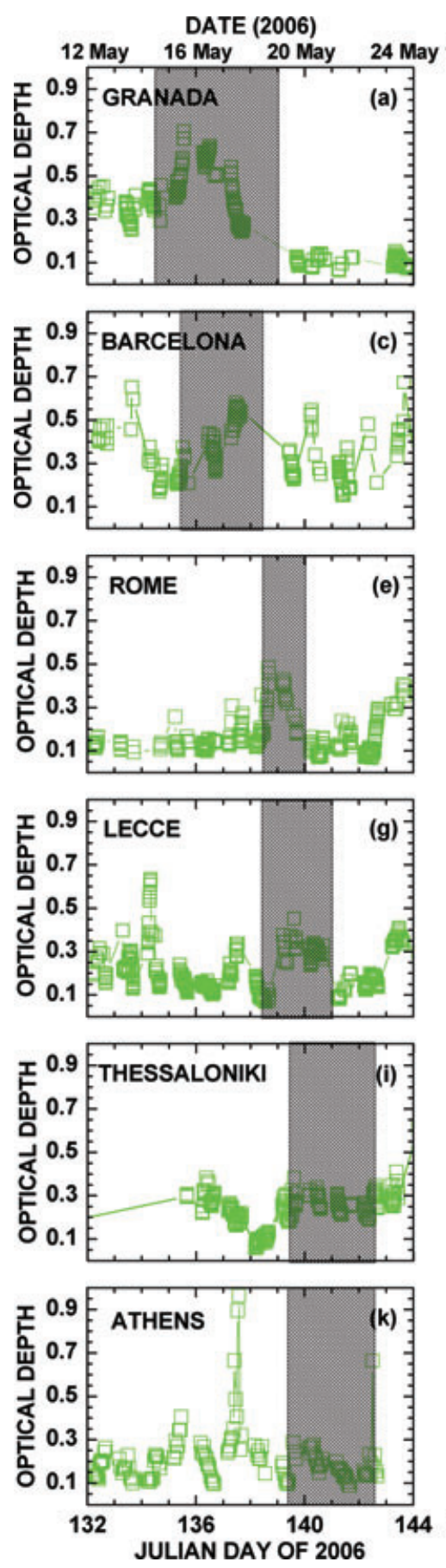
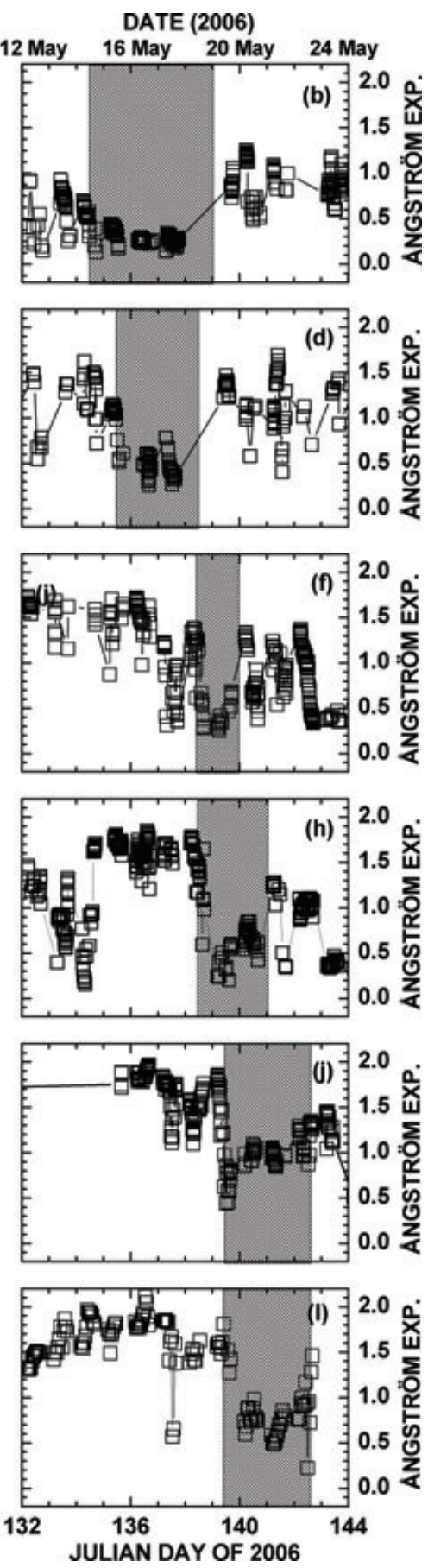

Fig. 4. Particle optical depths (OD) and Ångström exponents (å) measured with Sun photometer. Wavelengths for particle optical depth and wavelength ranges for Ångström exponents are as follows. (a,b) Granada: OD $(500 \mathrm{~nm}), \mathrm{a}(440 / 870 \mathrm{~nm}),(\mathrm{c}, \mathrm{d})$ Barcelona: OD (500 nm), å(440/870 nm), (e,f) Rome: OD (532 nm), å(440/870 nm), (g,h) Lecce: OD (500 nm), å(440/870 nm), (i,j) Thessaloniki: OD (500 nm), å(440/870 nm), (k,1) Athens: OD (500 nm), å(415/867 nm). The shaded areas denote the days on which desert dust most likely was observed at the different sites. optical depth were around 0.1 for the wavelength pair 380/500 $\mathrm{nm}$ and 0.23 for the wavelength pair $500 / 1020 \mathrm{~nm}$ on $13 / 14$ May 2006.

Figure 4 (a,b) shows the time series of particle optical depth and particle Ångström exponents measured in the 440-670 nm wavelength range at the Granada site. Particle optical depth increased from around 0.4 to around 0.6 between 14 May and 16 May 2006. At that time the particle Ångström exponent dropped from around 0.6 to approximately 0.2 , before it increased to maximum values of 1.2 on 20 May 2006 .

That change of particle optical depths and Ångström exponents shows that the dust plume had arrived over Granada. The numbers for particle optical depth are rather similar to the values measured with the AERONET Sun photometer at Ouarzazate. Ångström exponents are a bit larger, if we consider the wavelength pair $380 / 500 \mathrm{~nm}$. 

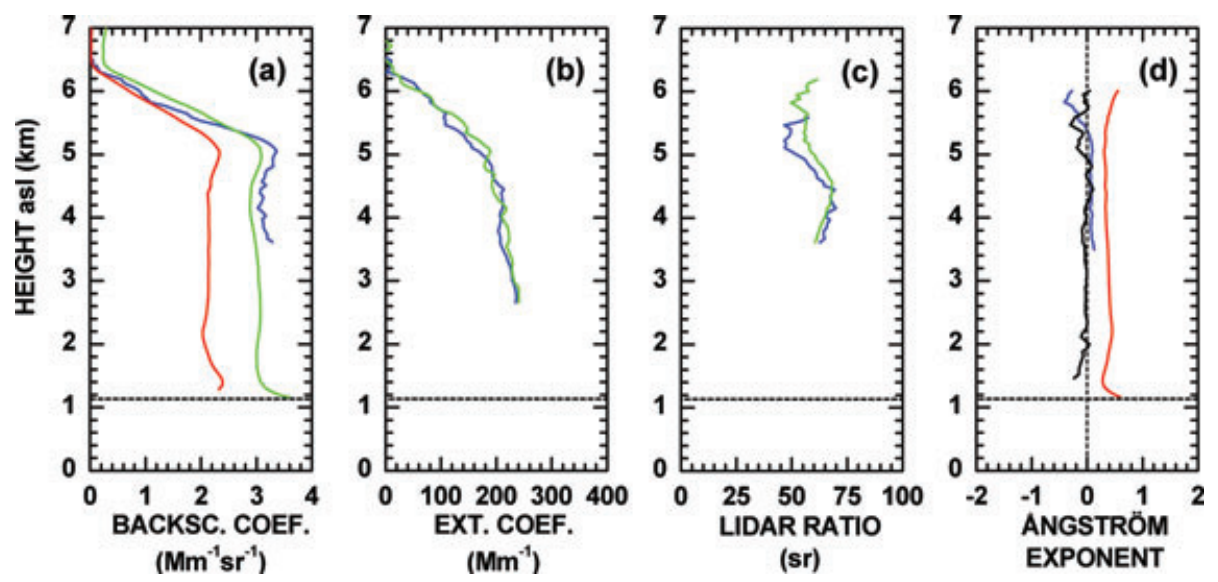

Fig. 5. Profiles of (a) particle backscatter coefficients (blue $=355 \mathrm{~nm}$, green $=532 \mathrm{~nm}$, red $=1064 \mathrm{~nm}$ ), (b) particle extinction coefficients (blue $=$ $355 \mathrm{~nm}$, green $=532 \mathrm{~nm}$ ), (c) particle lidar ratios (blue $=355 \mathrm{~nm}$, green $=532 \mathrm{~nm}$ ), (d) backscatter-related (blue $=$ wavelength pair $355 / 532 \mathrm{~nm}$, red = wavelength pair 532/1064 nm)) and extinction-related (black = wavelength pair 355/532 nm) Ångström exponents of the dust plume observed at Ouarzazate on 14 May 2006 from 20:12 to 21:09 UTC. The laser beam was tilted under $5^{\circ}$ from zenith. The horizontal line at $1133 \mathrm{~m}$ above sea level (asl) indicates the altitude of the field site.

Figure 4 (c, d) shows that particle optical depth over Barcelona increased from $0.15-0.3$ to $0.4-0.6$ between 14 May and 17 May 2006. During that time Ångström exponents decreased from maximum values of 1.5 to as low as 0.2 . In contrast to the Granada site we find a rather strong variability of the Ångström exponent.

We assume that the Barcelona site was only at the rim of the mineral dust plume and that the contribution of particles from anthropogenic pollution in the planetary boundary layer over Barcelona caused this strong variation of the Ångström exponent. Such particles are considerably smaller in size than mineral dust particles, and generally cause Ångström exponents $>1$, for example, Dubovik et al. (2002) and Müller et al. (2003). Another reason may have been sedimentation of larger dust particles, thus leaving on average smaller dust particles in the dust plume over Spain.

Sun photometer observations indicate that the dust plume arrived over Italy around 18 May 2006. At that time the dust plume had moved away from the Spanish lidar stations. The dust plume is identified by the increase of low optical depths of 0.1 to nearly 0.5 over the AERONET site in Rome around 18/19 May 2006. The Ångström exponent dropped from nearly 1.5 to as low as 0.3 during that time. Ångström exponents are nearly the same as the ones measured at Barcelona and Granada. We find a similar change of values at Lecce in South Italy. Particle optical depth increases from below 0.1 to around 0.4 around 18/19 May 2006. Ångström exponents dropped from above 1.5 on 18 May 2006 to minimum values of 0.2 on 19 May 2006.

Particle optical depth began to increase from $<0.1$ to nearly 0.4 at the Greek EARLINET station in Thessaloniki around 18/19 May 2006. The arrival of the dust plume again shows itself much clearer in the pronounced decrease of the Angström exponent. A similar pattern regarding the change of optical depth and Ångström exponent can be seen for the station in Athens.

\subsection{Lidar observations of the dust plume over Morocco}

Figure 5 exemplifies the geometrical and optical properties of the dust plume observed at Ouarzazate on 14 May 2006, that is, around the time when the dust began to move towards Spain. These properties did not change significantly, as can be seen from the measurement example for 15 May 2006 (Tesche et al., 2008).

The top height of the plume was around $6 \mathrm{~km}$ above sea level (a.s.1.) on 14 May 2006. According to data from radiosonde, which was launched during the time of the lidar observations, the plume was well mixed from bottom to top. Particle backscatter coefficients were as high as $3 \mathrm{Mm}^{-1} \mathrm{sr}^{-1}\left(\mathrm{Mm}=10^{6} \mathrm{~m}\right)$ at 355 and $532 \mathrm{~nm}$, and $2 \mathrm{Mm}^{-1} \mathrm{sr}^{-1}$ at $1064 \mathrm{~nm}$. Extinction coefficients were as high as $220 \mathrm{Mm}^{-1}$ at 355 and $532 \mathrm{~nm}$. The lidar ratio was nearly wavelength independent. Numbers vary between 50 and $65 \mathrm{sr}$ at 355 and $532 \mathrm{~nm}$. Extinction-related Ångström exponents (355/532 nm wavelength pair) and backscatter-related Ångström exponents (355/532 nm wavelength pair) are around 0. The backscatter-related Ångström exponents for the 532/1064 $\mathrm{nm}$ wavelength pair are around 0.5 . The linear particle depolarization ratio was $32 \%$ at $532 \mathrm{~nm}$ on that day (Freudenthaler et al., 2008).

\subsection{Lidar observations of the dust plume over South Europe}

Table 1 shows on which days the different lidar stations performed measurements. Figure 6 shows profiles of particle backscatter coefficients taken at the different lidar stations. The lidar observations at Ouarzazate show that the top of the mineral dust plume was at approximately $6 \mathrm{~km}$ above sea level. We find a similar height for the top of the mineral dust plume at most of the EARLINET stations in South Europe. 
Table 1. Days on which measurements were carried out at the EARLINET lidar stations.

\begin{tabular}{lcccccccc}
\hline Station & Granada & Barcelona & L'Aquila & Naples & Potenza & Lecce & Athens & Thessaloniki \\
Location & $37.2^{\circ} \mathrm{N}$, & $41.1^{\circ} \mathrm{N}$ & $42.4^{\circ} \mathrm{N}$ & $40.8^{\circ} \mathrm{N}$ & $40.6^{\circ} \mathrm{N}$ & $40.3^{\circ} \mathrm{N}$ & $37.9^{\circ} \mathrm{N}$ & $40.4^{\circ} \mathrm{N}$ \\
& $3.4^{\circ} \mathrm{W}$ & $2.2^{\circ} \mathrm{E}$ & $13.6^{\circ} \mathrm{E}$ & $14.3^{\circ} \mathrm{E}$ & $15.7^{\circ} \mathrm{E}$ & $18.1^{\circ} \mathrm{E}$ & $23.6^{\circ} \mathrm{E}$ & $22.9^{\circ} \mathrm{E}$ \\
\hline 13 May & $\mathrm{X}$ & & & & & & & \\
14 May & $\mathrm{X}$ & & & & & & & \\
15 May & $\mathrm{X}$ & $\mathrm{X}$ & & & & $\mathrm{X}$ & & \\
16 May & $\mathrm{X}$ & $\mathrm{X}$ & & & & $\mathrm{X}$ & & \\
17 May & $\mathrm{X}$ & $\mathrm{X}$ & & $\mathrm{X}$ & & $\mathrm{X}$ & & \\
18 May & $\mathrm{X}$ & $\mathrm{X}$ & $\mathrm{X}$ & $\mathrm{X}$ & $\mathrm{X}$ & $\mathrm{X}$ & & \\
19 May & & $\mathrm{X}$ & & $\mathrm{X}$ & $\mathrm{X}$ & $\mathrm{X}$ & & \\
20 May & & & & & & & & $\mathrm{X}$ \\
21 May & & & & & & & $\mathrm{X}$ & $\mathrm{X}$ \\
22 May & & & $\mathrm{X}$ & $\mathrm{X}$ & $\mathrm{X}$ & & $\mathrm{X}$ & $\mathrm{X}$ \\
\hline
\end{tabular}
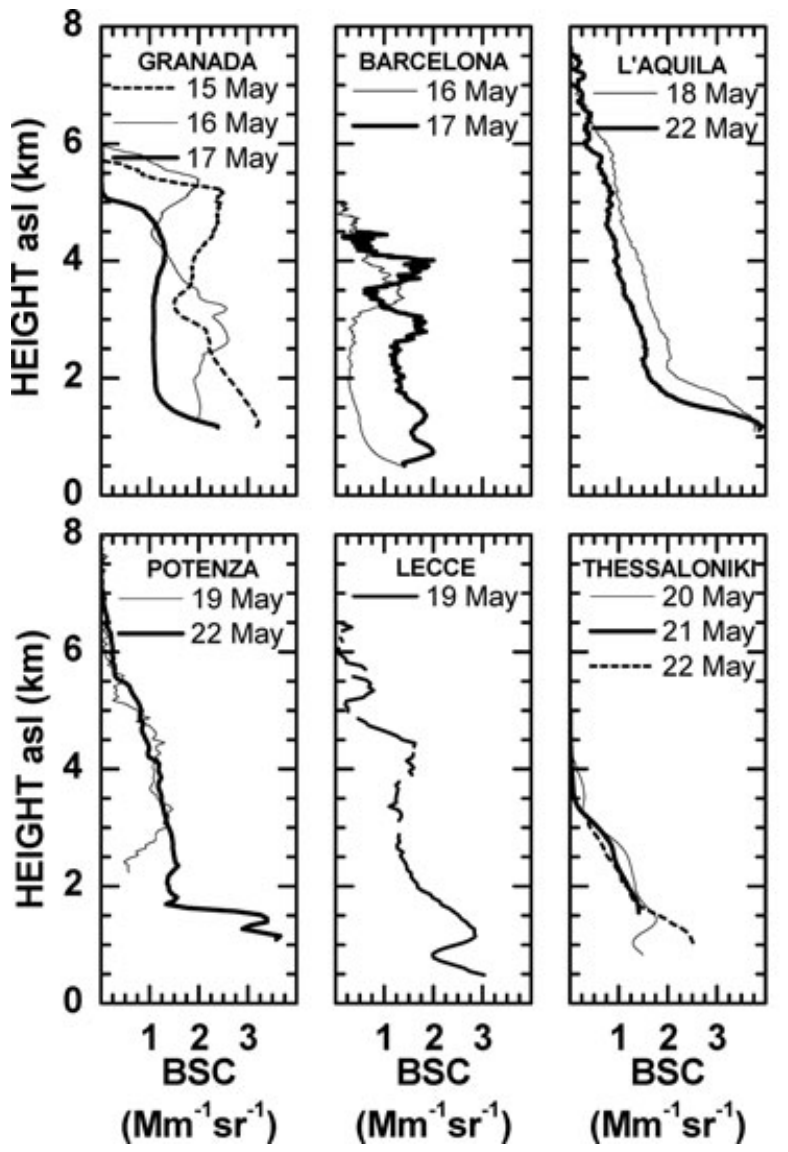

In this work we do not attempt to determine the exact bottom height of the dust plume. A separation of pure mineral dust in the free troposphere from anthropogenic pollution or mixtures of mineral dust with anthropogenic pollution in the planetary boundary layer is possible, for instance, on the basis of lidar profiles of particle depolarization ratios, or changes of particle Ångström exponents from low values (e.g. around 0, indicating

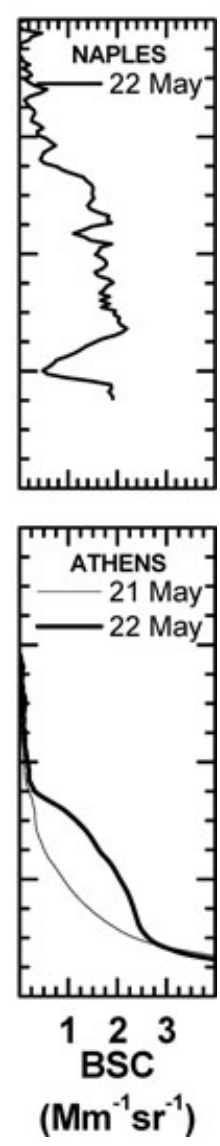

Fig. 6. Lidar profiles taken at the EARLINET stations. Station and measurement times are as follows. Granada (532 nm): 15 May 2006, 12:30-13:00 UTC (thick, dotted; $\mathrm{S}(532)=58 \mathrm{sr}$ ), 16 May 2006, 9:35-10:00 UTC (thin, solid; $\mathrm{S}(532)=58 \mathrm{sr}), 17$ May 2006, 11:00-11:30 UTC (thick, solid; S(532) = 58 sr). Barcelona (532 nm): 16 May 2006 6:18-19:19 UTC (thin, solid; S(532) $=50$ sr), 17 May 2006, 7:43-19:04 UTC (thick, solid; $\mathrm{S}(532)=50 \mathrm{sr})$. L'Aquila $(351 \mathrm{~nm})$ : 18 May 2006, 20:25-21:55 UTC (thin, solid), 22 May 2006, 20:00-21:30 UTC (thick, solid). Naples (532 nm): 22 May 2006, 19:02-19:32 UTC. Potenza: 19 May 2006, 1:30-2:00 UTC (thin, solid), 22 May 2006, 21:46-22:46 UTC (thick, solid). Lecce (351 nm): 19 May 2006, 18:45-19:27 UTC $(\mathrm{S}(351)=40 \mathrm{sr})$, Thessaloniki $(355 \mathrm{~nm}): 20$ May 2006, 17:29-18:00 UTC (thin, solid), 21 May 2006, 18:37-19:00 UTC (thick, solid), 22 May 2006, 18:06-18:35 UTC (dashed). Athens (532 nm): 21 May 2006, 16:04-17:00 UTC (thin, solid; S(532) $=40$ sr), 22 May 2006, 12:04-12:53 UTC (thick, solid; $\mathrm{S}(532 \mathrm{sr})=40 \mathrm{sr})$.

large mineral dust particles) to high values (e.g. around 1 or higher, indicating small anthropogenic particles). For many of the lidar stations we do not have that comprehensive set of data. However, strong changes of the particle backscatter coefficients which were provided by all stations involved in this study, occur around the top height of the planetary boundary layer. These changes give us at least an estimate on the approximate bottom 
height of the free-tropospheric mineral dust plume. Mineral dust is likely less affected with anthropogenic pollution.

Figure 6 shows that the dust plume reached a top height of 5$6 \mathrm{~km}$ at the Granada station. Profiles of the particle backscatter coefficient show that the top of the dust plume was around $5 \mathrm{~km}$ height over Barcelona on 16 and 17 May 2006.

Four Italian lidar stations measured during the dust event. Lidar profiles taken at L'Aquila on 18 May and 22 May 2006 show that mineral dust was present in heights of around 6$6.5 \mathrm{~km}$. The bottom height of the mineral dust plume is at approximately $2 \mathrm{~km}$ a.s.1. A similar top and bottom height was also observed at the Naples station on 22 May 2006. Top heights of approximately $5.5-6.5 \mathrm{~km}$ of the dust plume were reported from the EARLINET station in Potenza on 19 and 22 May 2006. The bottom height of that part of the dust plume that we believe to be nearly free of anthropogenic pollution was approximately $2.5 \mathrm{~km}$ on 19 May 2006 and $2 \mathrm{~km}$ on 22 May 2006. The determination of the bottom height of the dust plume is more exact in the case of the Potenza station because it provides us with a rather comprehensive set of optical properties of the dust plume. In the following description of the results from Potenza we shall therefore concentrate on those height ranges. Lidar observations were carried out at Lecce from 15 May to 19 May. According to the observations there was no dust present until 18 May 2006. The dust plume was observed on 19 May 2006. The top height was around $5.5 \mathrm{~km}$, with a closed cloud deck at $5.5 \mathrm{~km}$ height on that day.

Interestingly the lidar profiles that were taken at the Greek lidar stations in Thessaloniki and Athens on 20, 21 and 22 May 2006 show a considerably lower top height of the dust plume. Both stations report a maximum height of $4 \mathrm{~km}$ above sea level. An exact determination of the bottom height is difficult, as there certainly was a mixture of dust with anthropognic pollution during the observational period.

Figure 7 shows vertical profiles of particle lidar ratios measured at 351/355 and $532 \mathrm{~nm}$. At L'Aquila the lidar ratio was measured at $351 \mathrm{~nm}$. On 18 May 2006 we measured $56 \pm 10 \mathrm{sr}$ between 2500 and $5000 \mathrm{~m}$ height. Lower mean values of $44 \pm$ 10 sr were measured in the same height range on 22 May 2006. Lidar ratios of 40-50 sr at $355 \mathrm{~nm}$ were measured at Naples and Potenza on 22 May 2006. In summary we find a comparably large range of lidar ratios at L'Aquila, Naples, and Potenza. The large variation does not allow us to decide whether the lidar ratio at $355 \mathrm{~nm}$ changed with time of transport.

The Potenza station also delivers the lidar ratio at $532 \mathrm{~nm}$. Lidar ratios varied around 55-60 sr both on 19 and 22 May. These values are similar to those measured at Ouarzazate. Lidar ratios measured at Ouarzazate are wavelength-independent values. There is no clear indication about the lidar ratio wavelength dependence for the Potenza data. A main difference can be observed in the homogeneity of the aerosol dust layer observed at Potenza on 19 and 22 May. The lidar ratio values at 355 and 532 $\mathrm{nm}$ are almost constant within the dust layer altitude range for 22 May, whereas the lidar ratios are highly variable on 19 May 2006. This gives us an indication that the dust is well mixed in the dust layer on 22 May, probably because on this day a more direct transport from the source region occurred.

The lidar ratio was measured at $355 \mathrm{~nm}$ at Thessaloniki. According to backward trajectories, Sahara dust seemed to be present over Thessaloniki at heights above $2.5 \mathrm{~km}$ on 20 May. However, we find a rather low lidar ratio of 40-45 sr For comparison we measured 50-60 sr at Ouarzazate on 14-15 May 2006. The next day, 21 May, we find a larger lidar ratio of around 65 $\mathrm{sr}$ in a small layer around $2.5 \mathrm{~km}$ height. The trajectory analysis indicates dust transport also at lower altitudes over Thessaloniki. We assume that on 21 May 2006 there was a mixture of dust with absorbing urban aerosols in the lower heights, see also Papayannis et al. (2008). On 22 May 2008 back-trajectory analysis still suggests traces of dust over Thessaloniki. In fact the lidar ratio of 55-65 sr (at $355 \mathrm{~nm}$ ) matches best to the lidar ratio observed at Ouarzazate, although it is very likely that also on that day dust was mixed with local pollution.

Figure 8 shows the comparison of the backscatter-coefficientrelated and the extinction-coefficient-related Ångström
Fig. 7. Profiles of particle lidar ratios taken at L'Aquila, Naples, Potenza, and Thessaloniki. Measurement times are the same as the ones for the profiles of the backscatter coefficients, see Fig 6. Profiles in blue colour denote lidar ratios at $355 \mathrm{~nm}$ ( $351 \mathrm{~nm}$ in the case of the station at L'Aquila). Profiles in green colour denote lidar ratios at $532 \mathrm{~nm}$.
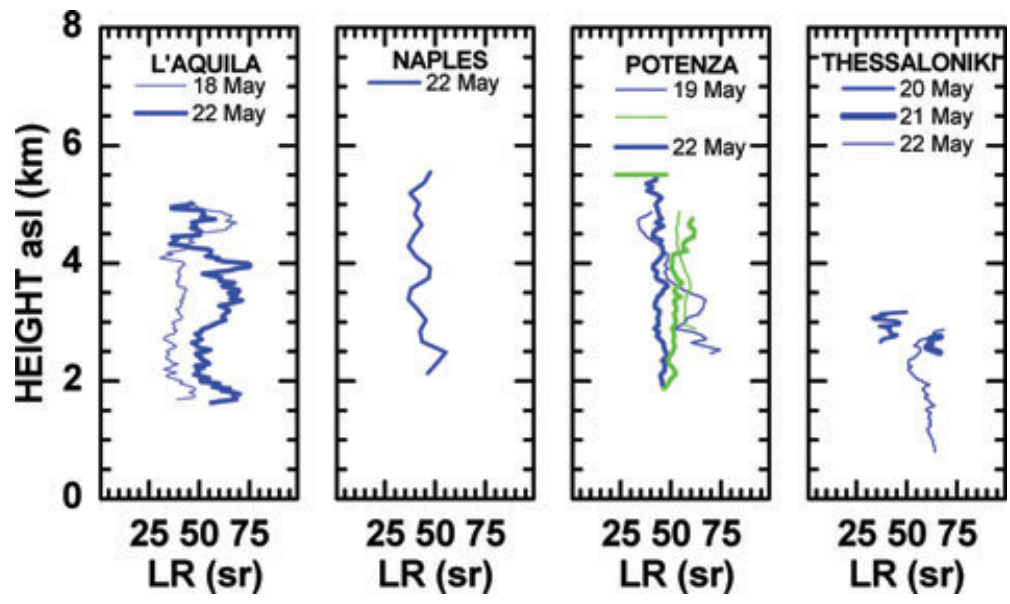

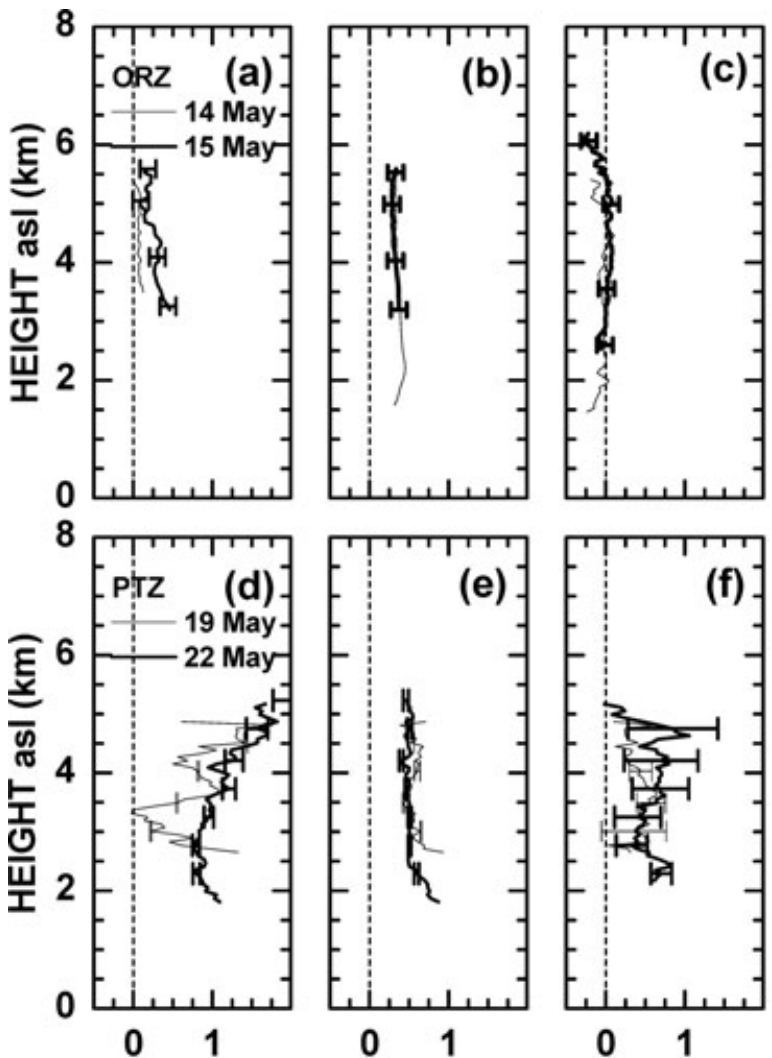

$\beta$-ANG. EXP. $\beta$-ANG. EXP. $\alpha$-ANG. EXP. $(355 / 532 \mathrm{~nm})(532 / 1064 \mathrm{~nm})(355 / 532 \mathrm{~nm})$

Fig. 8. Profiles of particle Ångström exponents taken at Ouarzazate and Potenza. Shown are the backscatter-related Ångström exponents for the wavelength pair $355 / 532 \mathrm{~nm}$ for (a) Ouarzazate and (d) Potenza, and 532/1064 nm for (b) Ouarzazate and (e) Potenza, and the extinction-related Ångström exponent for the wavelength pair 355/532 $\mathrm{nm}$ for (c) Ouarzazate and (f) Potenza. Error bars denote one-standard-deviation.

exponents at Ouarzazate and Potenza, respectively. The columnmean value of the backscatter-coefficient-related Ångström exponents at Ouarzazate is approximately 0 at the $355 / 532$ wavelength pair and 0.5 at the 532/1064 nm wavelength pair. We find a column-mean value of approximately 0 for the extinctioncoefficient-related Ångström exponent.

The backscatter-coefficient-related Ångström exponent varies from 0.5 to 1 (wavelength pair $355 / 532 \mathrm{~nm}$ ) at Potenza. The backscatter-coefficient-related Ångström exponents at the $532 / 1064 \mathrm{~nm}$ wavelength pair are around 0.5 , in agreement with values observed at Ouarzazate. The extinction-coefficientrelated Ångström exponent varies along the profile from 0.2 to approximately 0.8 at Potenza. The mean value is 0.5 , which is in agreement with values measured with AERONET Sun photometer in Rome and Lecce during this Saharan dust event.

The larger values of the Ångström exponents at 355/532 nm at Potenza suggest that the concentration of small particles, that is, particles in the fine mode fraction of the particle size distribution was higher in the far-field of the dust source region compared to the near field in North Africa. Sedimentation processes may have led to this increase of ratio of fine-to-coarse mode particles of the particle size distribution. Another reason may be an accumulation of anthropogenic/urban particles in the dust plume over Continental Europe.

We observe a higher variability of the profiles of the Angström exponents and the lidar ratios at Potenza on 19 May compared to the profiles measured at Potenza on 22 May 2006. This low variation underlines once more that aerosol particles were well mixed in the altitude range of the dust layer on 22 May, compared to the situation on 19 May when the plume probably was more inhomogeneously distributed along the vertical. This difference might be related to different paths the dust plume took before arriving over Potenza. On 19 May the dust plume came from northern Italy after passing over Spain. On 22 May the dust reached Potenza directly from western Africa after passing over the Mediterranean Sea.

\section{Results from transport modelling: comparison to experimental data}

\subsection{Optical depth from Sun photometer}

Figure 9 shows in more detail the comparison of modelled particle optical depth and optical depth measured with Sun photometer at the South European lidar stations. The model results present instanteneous hourly data. The Sun photometer measurements describe particle optical depth of the total atmospheric column.

With regard to the model runs we show two values for optical depth for each time step. We obtain a band of modelled optical depths. The lower values at each time step describes optical depth of the pure dust. The upper values at each time step describe total optical depth, that is, optical depth of background aerosol particles is included. Background optical depth, however, is not computed by the model. We add a constant value of optical depth of the background aerosol particles. The background values that we use for each station are taken from the aerosol climatology of Tanré et al. (1984). These optical depths are static but variable in space. We took the value for each measurement site, respectively. These values may overestimate the contribution of tropospheric background aerosol particles, and consequently may lead to an overestimation of total optical depth.

The model results show a strong increase of optical depth at Granada on 13/14 May 2006, in accordance with the experimental data. The increase however is less steep than what the model output indicates. Optical depth peaks at nearly the same time at which the modelled optical depth reaches its maximum. In contrast to the model results, the measured optical depth drops to lower values considerably earlier. 

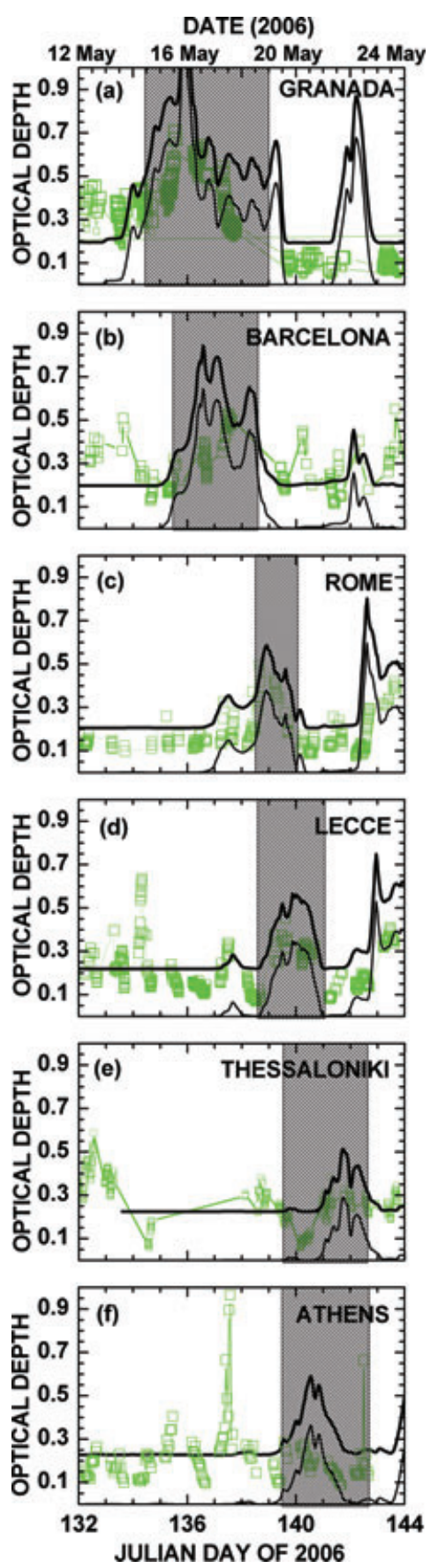

Fig. 9. Comparison of particle optical depth measured with Sun photometers and determined with LM-MUSCAT-DES. Shown are the results for the stations at (a) Granada, (b) Barcelona, (c) Rome, (d) Lecce, (e) Thessaloniki and (f) Athens. We show total particle optical depth from Sun photometer (green symbols) and from the model (thick line, upper limit), and dust optical depth only (thin line, lower limit).
Figure 9 shows that the climatological background value that has been assumed in the model calculations is too large. This overestimation of the background values can be seen in the simulations for all other sites that we considered in our study.

The comparison of the modelling results with the observations is more difficult in the case of the station at Barcelona. Measured optical depth is very variable in the time period of interest. The model shows the peak of dust optical depth on 16 May 2006, whereas optical depth measured with Sun photometer peaks 1 $\mathrm{d}$ later. Nevertheless the model catches the period of increased optical depth fairly well.

Regarding the AERONET station in Rome the model results and the experimental data indicate a similar time of arrival of the dust plume, that is, between 17 and 18 May 2006. We emphasize that the determination regarding the arrival of the dust plume is mostly based on our knowledge of the Ångström exponents.

The model predicts the presence of mineral dust at the AERONET-EARLINET station in Lecce in the same time frame as is shown by the AERONET observations (afternoon of 18 May until 20 May 2008). There were two more short time periods (14 May 2006 and 17 May 2006) with increased values of optical depth. However, the dust simulations and the OMI aerosol index do not show these two dust particles. In fact, the Ångström exponent was rather high on 17 May 2006. On 14 May 2006 the Ångström exponent was low, which means that dust may have been present, in contradiction to the data from OMI and the model calculations. We can only speculate on the reason for the difference. Dust from local sources or a strong contribution from marine particles may be the cause.

The model results suggest the presence of mineral dust between 19 and 21 May 2006. Sun photometer measurements of optical depth at the Greek station in Athens do not give a clear sign on the presence of mineral dust. It is the Ångström exponent that suggests the presence of the dust plume (see Fig. 4c).

The model does not show if traces of dust were present at noontime of 22 May 2006. On that specific day we observed two short spikes in the experimental data. Particle optical depth was $0.3-0.4$ (in our higher resolution data sets in which measurements were done every minute), imposed on a background value of $0.1-0.15$, and a much higher value of 0.65 around noon time. These peaks are possibly related to remaining filaments of dust following the main event.

The model predicts mineral dust over Thessaloniki in the same timeframe as for Athens. The temporal evolution and dust optical depth measured with Sun photometer are well reproduced with the model, if we keep in mind that the climatological background value of optical depth is too high.

\subsection{Vertical profiles from lidar}

LM-MUSCAT-DES was also tested with regard to the reproduction of profiles of particle extinction coefficients. The results for Morocco are discussed by Heinold et al. (2008). Figure 10 

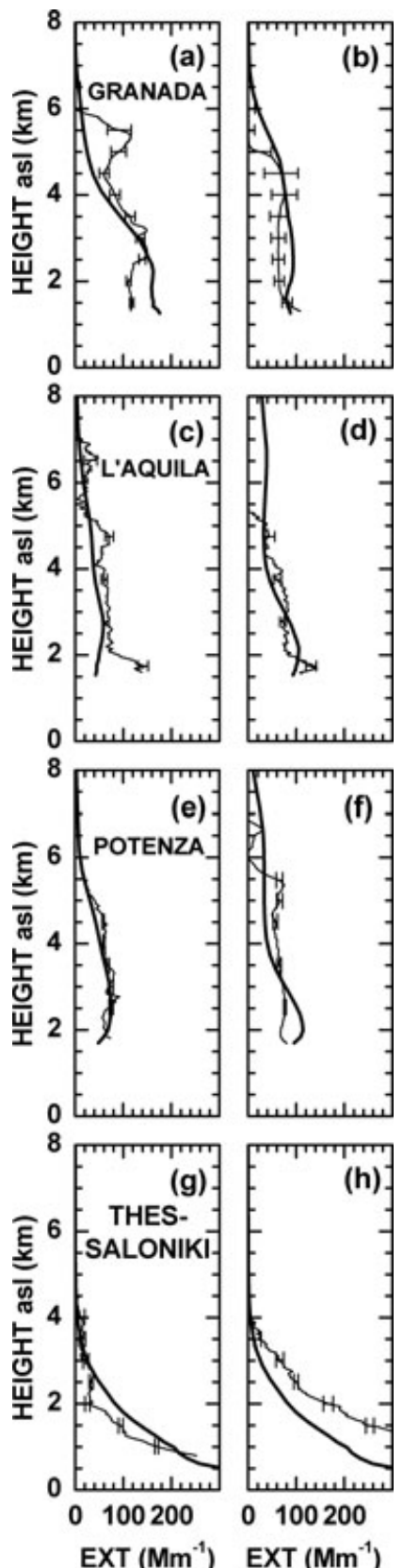

Fig. 10. Comparison of extinction profiles derived from lidar observations (thin solid lines with error bars) and derived from the model simulations (thick solid lines). Shown are profiles of the particle extinction coefficient at Granada on (a) 16 May and (b) 17 May 2006 at $532 \mathrm{~nm}$. Particle extinction profiles were measured with Raman lidar at L'Aquila on (c) 18 May and on (d) 22 May at $351 \mathrm{~nm}$ wavelength, at Potenza on (e) 19 May and (f) 22 May 2006 at $532 \mathrm{~nm}$, and at Thessaloniki on (g) 21 May and (h) on 22 May at $355 \mathrm{~nm}$. Measurement times are the same as in Fig. 6. Error bars denote one-standard-deviation. The profiles from the model results only describe that part of the signals that is caused by the mineral dust. shows results for profiles of particle extinction coefficients measured at the Italian stations at L'Aquila and Potenza, and the Greek station at Thessaloniki. The incomplete overlap between transmitted laser beam and receiver-field-of-view of the detector telescope restricts the minimum height to which extinction profiles can be measured at these sites.

For completeness we also show results for the Spanish station at Granada. Extinction profiles could not be measured. Extinction profiles were obtained from profiles of particle backscatter coefficients. For the conversion from dust particle backscatter into dust particle extinction coefficients we use a height independent lidar ratio of $58 \mathrm{sr}$ at $532 \mathrm{~nm}$.

In general the model is not capable of reproducing the exact shape of the profiles of the particle extinction coefficients. The modelled profiles however catch the main features of the dust extinction profiles. We have to keep in mind that the vertical resolution of the model is not as fine as the vertical resolution of the lidar observations. For instance, the model resolution is $\approx 200 \mathrm{~m}$ for a particle layer at $1.5 \mathrm{~km}$ a.s.l. The resolution is $\approx 600 \mathrm{~m}$ for a particle layer at $8 \mathrm{~km}$ a.s.1.

Deviations exist with respect to the profile of the particle extinction coefficient at Granada for 16 May 2006. In that case the model does not reproduce the dust plume between 4.5 and $6 \mathrm{~km}$ height. In the case of the measurement from 17 May 2006 the dust model does not catch the top of the dust layer at $5 \mathrm{~km}$, but rather sets it at above $8 \mathrm{~km}$ height.

The modelled profiles of the particle extinction coefficients at L'Aquila underestimate the values measured on 18 May 2006. However the overall decrease of the extinction coefficient with height is reproduced sufficiently well. The model profile of 22 May 2006 sets the top of the dust layer at approximately $10.5 \mathrm{~km}$. The fine structure of the profile cannot be reproduced, which has to be attributed to the lacking spatial resolution of the model.

The extinction coefficient profile measured at Potenza on 19 May 2006 is very well reproduced with the model. The top of the dust plume is resolved very well. In contrast, the extinction coefficient profile that was measured on 22 May 2006 cannot be resolved well. Extinction coefficients are overestimated below $3 \mathrm{~km}$ height, and underestimated above that height.

The shape of the extinction profiles from the model agrees well with the extinction profiles measured at Thessaloniki on 21 May and 22 May 2006. The absolute values of the extinction coefficients are overestimated by the model for the measurement on 21 May 2006. The model dust extinction coefficients are strongly underestimated on 22 May 2006.

The measurements at Thessaloniki present a rather difficult case, because we most certainly observed mixtures of mineral dust with urban pollution. A quantification of the contribution of dust to the extinction coefficients is rather uncertain. For instance, the strong underestimation of modelled light-extinction by mineral dust on 22 May 2006 may rather result from the 
strong contribution of anthropogenic pollution to the measured extinction coefficients.

\section{Summary}

We presented a case of long-range transport of mineral dust from Northwest Africa to South Europe. That case study is unique as it is for the first time that coherent observations of mineral dust were done with a network of lidar stations in the far field of the North African source regions, while at the same time a detailed characterization of such a mineral dust plume could also be carried out near the North African source region.

The dust plume traveled from Morocco to the Iberian peninsula, and from there to Italy and Greece. The event lasted for approximately $10 \mathrm{~d}$. We do not see large differences of the top height of the dust layer over Morocco, Spain, and Italy. In general we find heights between 5.5 and $6.5 \mathrm{~km}$ a.s.l. However, we find a considerably lower top height of $4 \mathrm{~km}$ above the two Greek lidar stations that were considered in our study.

AERONET Sun photometer observations were carried out at the Moroccan field site in Ouarzazate, and at the lidar stations in Europe. Generally the arrival of the dust plume at the lidar stations was clearly visible from a drop of the Ångström exponents from values above 1 to values less than 1 . The Ångström exponents from the Sun photometer observations do not describe the pure dust over Europe, because of the presence of anthropogenic pollution in the boundary layer.

Parameters of the dust plume were determined with EARLINET lidars at the Sun photometer sites. A clear separation of mineral dust and anthropogenic pollution at the lidar stations is rather difficult, too. The lack of multiwavelength lidar data and particularly the fact that no dust particle depolarization ratios were measured is a drawback, and can be only overcome to some extend with a detailed analysis of the meteorological situation, backward trajectory analysis, and dust tracer simulations. For that reason we mainly focused our discussion on lidar data above the planetary boundary layer, where we have a lower impact of anthropogenic pollution. However, it is rather clear that there was also dust in the planetary boundary layer, as the example for Thessaloniki shows. We obtained particle backscatter and extinction coefficients, Ångström exponents, and lidar ratios. The lidar observations show that dust particle Ångström exponents over South Europe are larger than over Morocco. For instance, the Ångström exponents that were derived from particle extinction coefficients measured at 355 and $532 \mathrm{~nm}$ are 0 at the Moroccan field site. Values are 0.5-1 in South Italy. Backscatterrelated Ångström exponents are 0.2-0.3 in Morocco, and 0.5-1 over Potenza in South Italy.

We find different dust lidar ratios over Morocco and South Europe; see also Papayannis et al. (2008) for measurement examples. The reason for that difference is not absolutely clear. We think that the dust plume was only little affected with anthropogenic pollution over the Italian stations. Some natural varia- tion of the dust lidar ratio may be one factor. The Greek stations rather likely measured mineral dust, mixed with anthropognic pollution.

The measurements at the lidar station at Potenza suggest a slight wavelength dependence of the dust lidar ratio. Measurements of the parameter were done at 355 and $532 \mathrm{~nm}$. We measured wavelength-independent lidar ratios at Morocco.

This study offered us the opportunity to test the performance of the dust model LM-MUSCAT-DES regarding the prediction of optical depth in the far field of the North African dust sources. We compare optical depth from the model to optical depth measured with the Sun photometers. The model results show similarities to the experimental data regarding the presence of dust over the different sites. The model also sets the arrival of dust over each site approximately at the same time at which Sun photometer data indicate the presence of mineral dust. Dust optical depths from the modelling agree to some extent to the optical depths measured at some sites.

We furthermore tested the model against vertical profiles of particle extinction coefficients that were measured with the lidars. The model reproduced the vertical variation of the particle extinction coefficients for some measurement cases. In some other cases the variation was not reproduced. Deviations, for instance, occur as soon as the profiles show multilayered features. Some deviations between the model results and the lidar profiles occur due to too strong vertical mixing in the transport model. This feature is improved in a new model version, which will be implemented for future simulations. The exact top height of the dust plume was missed in some cases. That error may be due to an insufficient vertical resolution of the model.

\section{Acknowledgments}

The financial support for EARLINET by the European Commission under grant RICA-025991 is gratefully acknowledged. This study was also funded by the German Research Foundation (Deutsche Forschungsgemeinschaft) within the Research Group SAMUM under grant FOR 539. We thank P. Gobbi for providing the data taken with AERONET Sun photometer at Rome.

\section{References}

Ansmann, A., Wandinger, U., Riebesell, M., Weitkamp, C. and Michaelis, W. 1992. Independent measurement of extinction and backscatter profiles in cirrus clouds by using a combined Raman elastic-backscatter lidar. Appl. Opt. 31, 7113-7131.

Ansmann, A., Bösenberg, J., Chaikovsky, A., Comerón, A., Eckhardt, S. and co-authors. 2003. Long-range transport of Saharan dust to northern Europe: The 11-16 October 2001 outbreak observed with EARLINET. J. Geophys. Res. 108, doi:10.1029/2003JD003757.

Ansmann, A. and Müller, D. 2005. Lidar and atmospheric aerosol particles. In: Lidar. Range-Resolved Optical Remote Sensing of the Atmosphere (ed. C. Weitkamp), Springer, New York, 105-141. 
Berge, E. 1997. Transboundary air pollution in Europe. In: MSC-W Status Report 1997, Part 1 and 2, EMEP/MSC-W Report 1/97, Technical report, Oslo, Norway.

Bösenberg, J., Alpers, M., Althausen, D., Ansmann, A., Böckmann, C. and co-authors. 2001. The German Aerosol Lidar Network: Methodology, Data, Analysis, Report No. 317, Technical report, Hamburg, Germany.

Bösenberg, J., Matthias, V., Amodeo, A., Amoiridi, V., Ansmann, A. and co-authors. 2003. EARLINET: A European Aerosol Research Lidar Network to Establish an Aerosol Climatology, Report No. 348, Technical report, Hamburg, Germany.

Doms, G. and Schättler, U. 2002. A description of the nonhydrostatic regional model LM, Technical Report Part I: Dynamics and $\mathrm{Nu}$ merics, Deutscher Wetterdienst, Offenbach, Germany. available at http://www.cosmo-model.org/.

Dubovik, O. and King, M. D. 2000. A flexible inversion algorithm for retrieval of aerosol optical properties from sun and sky radiance measurements. J. Geophys. Res. 105, 20 673-20 696.

Dubovik, O., Smirnov, A., Holben, B. N., King, M. D., Kaufman, Y. J. and co-authors. 2000. Accuracy assessments of aerosol optical properties retrieved from Aerosol Robotic Network (AERONET) Sun and sky radiance measurements. J. Geophys. Res. 105, 97919806.

Dubovik, O., Holben, B. N., Eck, T. F., Smirnov, A., Kaufman, Y. J. and co-authors. 2002. Variability of absorption and optical properties of key aerosol types observed in worldwide locations. J. Atmos. Sci. 59, 590-608.

Freudenthaler, V., Esselborn, M., Wiegner, M., Heese, B., Tesche, M. and co-authors. 2008. Depolarization ratio profiling at several wavelengths in pure Saharan dust during SAMUM 2006. Tellus 61B, doi:10.1111/j.1600-0889.2008.00396.x.

Gerasopoulos, E., Andreae, M. O., Zerefos, C. S., Andreae, T. W., Balis, D. and co-authors. 2003. Climatological aspects of aerosol optical properties in Northern Greece. Atmos. Chem. Phys. 3, 2025-2041.

Heinold, B., Helmert, J., Hellmuth, O., Wolke, R., Ansmann, A. and co-authors. 2007. Regional modeling of Saharan dust events using LM-MUSCAT: model description and case studies. J. Geophys. Res. 112, doi:10.1029/2006JD007443.

Heinold, B., Tegen, I., Esselborn, M., Kandler, K., Knippertz, P. and coauthors. 2008. Regional Saharan Dust Modelling during the SAMUM 2006 Campaign. Tellus 61B, doi:10.1111/j.1600-0889.2008.00387.x.

Helmert, J., Heinold, B., Tegen, J., Hellmuth, O., and Wendisch, M. 2007. On the direct and semi-direct effect of Saharan dust over Europe: a modeling study. J. Geophys. Res. 112, doi:10.1029/2006JD007444.

Holben, B. N., Eck, T. F., Slutsker, I., Tanré, D., Buis, J. P. and coauthors. 1998. AERONET - a federated instrument network and data archive for aerosol characterization. Remote Sens. Environ. 66, 1-16.

Holben, B. N., Tanré, D., Smirnov, A., Eck, T. F., Slutsker, I., D. and co-authors. 2001. An emerging ground-based aerosol climatology: aerosol optical depth from AERONET. J. Geophys. Res. 106, 12 06712097.

Jakobson, H. A., Jonson, J. E. and Berge, E. 1997. The multi-layer Eulerian model: model description and evaluation of transboundary fluxes of sulphur and nitrogen species for one year. EMEP/MSC-W Note 2/97, Technical report, Oslo, Norway.

Kalashnikova, O. V. and Sokolik, I. N. 2002. Importance of shapes and compositions of wind-blown dust particles for remote sensing at solar wavelengths. Geophys. Res. Lett. 29, doi:10.1029/2002GL014947.
Knippertz, P., Ansmann, A., Althausen, D., Müller, D., Tesche, M. and co-authors. 2008. Dust mobilization and transport in the northern Sahara during SAMUM 2006. Tellus 61B, doi:10.1111/j.16000889.2008.00380.x.

Levelt, R. F. 2002. OMI Algorithm theoretical basis document Volume 1: OMI Instrument, Level 0-1b processor, calibration \& operations, Technical report, Greenbelt, MD.

Majewski, D., Liermann, D., Prohl, P., Ritter, B., Buchhold, M. and co-authors. 2002. The operational global icosahedral-hexagonal gridpoint model GME: description and high-resolution tests. Mon. Wea. Rev. 130, 319-338.

Matthias, V., Freudenthaler, V., Amodeo, A., Balin, I., Balis, D. and coauthors.Wang, X. 2004. Aerosol lidar intercomparison in the framework of the EARLINET project. 1. Instruments. Appl. Opt. 43, 961976.

Matthias, V., Freudenthaler, V., Amodeo, A., Balin, I., Balis, D. and co-authors. 2004. Aerosol lidar intercomparison in the framework of the EARLINET project. 1. Instruments: erratum. Appl. Opt. 43, 2578-2579.

Mishchenko, M. I., Travis, L. D., Kahn, R. A. and West, R. A. 1997. Modeling phase functions for dustlike tropospheric aerosols using a shape mixture of randomly oriented polydisperse spheroids. J. Geophys. Res. 102, 16831-16847.

Mona, L., Amodeo, A., Pandolfi, M. and Pappalardo, G. 2006. Saharan dust intrusions in the Mediterranean area: three years of Raman lidar measurements. J. Geophys. Res. 111, doi:10.1029/2005JD006569.

Müller, D., Mattis, I., Wandinger, U., Althausen, D., Ansmann, A. and co-authors. 2003. Saharan dust over a Central European EARLINETAERONET site: combined observations with Raman lidar and Sun photometer. J. Geophys. Res. 108, doi:10.1029/2002JD002918.

Papayannis, A., Balis, D., Amiridis, V., Chourdakis, G., Tsaknakis, G. and co-authors. 2005. Measurements of Saharan dust aerosols over the Eastern Mediterranean using elastic backscatter-Raman lidar, spectrophotometric and satellite observations in the frame of the EARLINET project. Atmos. Chem. Phys. 5, 2065-2079.

Papayannis, A., Amiridis, V., Mona, L., Tsaknakis, G., Balis, D. and co-authors. 2008. Systematic lidar observations of Saharan dust over Europe in the frame of EARLINET (2000-2002). J. Geophys. Res. 113, doi:10.10129/2007JD9028.

Schmetz, J., Pili, P., Tjemkes, S., Just, D., Kerkmann, J. and co-authors. 2002. An introduction to Meteosat Second Generation (MSG). Bull. Am. Meteorol. Soc. 83, 977-992.

Sinyuk, A., Torres, O. and Dubovik, O. 2003. Combined use of satellite and surface observations to infer the imaginary part of Saharan dust. Geophys. Res. Lett. 30. doi:10.1029/2002GL016189.

Sokolik, I. N. and Toon, O. B. 1999. Incorporation of mineralogical composition into models of the radiative properties of mineral aerosol from UV to IR wavelengths. J. Geophys. Res. 104, 9423-9444.

Tanré, D., Geleyn, J. F. and Slingo, J. M. 1984, In: Aerosols and Their Climatic Effects, (ed. A. Deepak), Hampton, VA, 133-177.

Tegen, I., Harrison, S. P., Kohfeld, K., Prentice, I. C., Coe, M. and coauthors. 2002. Impact of vegetation and preferential source areas on global dust aerosol: results from a model study. J. Geophys. Res. 107, doi:10.1029/2001JD000963.

Tesche, M., Ansmann, A., Müller, D., Althausen, D., Mattis, I. and coauthors. 2008. Vertical profiling of Saharan dust with Raman lidars and airborne HSRL in southern Morocco during SAMUM. Tellus 61B, doi:10.1111/j.1600-0889.2008.00390.x. 
Tiedtke, M. 1989. A comprehensive mass flux scheme for cumulus parameterisation in large-scale models. Mon. Wea. Rev. 117, 17791799.

Wolke, R., Hellmuth, O., Knoth, O., Schröder, W. and Renner, E. 2004a. The parallel model system $1 \mathrm{~m}$-muscat for chemistry-transport simulations: Coupling scheme, parallelization and application, in: Parallel computing: Software technology, algorithms, architectures, and applications. In: Advanced in Parallel Computing (eds G. R. Joubert, W. E. Nagel, F. J. Peters, and W. V. Walter), Elsevier, The Netherland, 363-370.
Wolke, R., Hellmuth, O., Knoth, O., Schröder, W., Heinrich, B. and coauthors. 2004b. The chemistry-transport modeling system lm-muscat: description and citydelta applications, in: air pollution modeling and its application xvi. In: Proceedings of twenty-sixth NATO/CCMS international technical meeting on air pollution modeling and its application (eds C. Borrego, and S. Incecik), Kluwer Academic/Plenum Publishers, New York, 427-439.

Zhang, L., Gong, S., Padro, J. and Barrie, L. 2001. A size-segregated particle dry deposition scheme for an atmospheric aerosol module. Atmos. Env. 35, 549-560. 